\title{
Por um ensino decolonial de literatura
}

\section{Towards a Decolonial Teaching of Literature}

Rodrigo Corrêa Martins Machado*

*Universidade Federal de Ouro Preto (UFOP), Ouro Preto, Minas Gerais / Brasil

rodrigo.machado@ufop.edu.br

https://orcid.org/0000-0001-7269-1996

Ivanete Bernardino Soares**

**Universidade Federal de Ouro Preto (UFOP), Ouro Preto, Minas Gerais / Brasil iva.bsoares@ufop.edu.br

https://orcid.org/0000-0002-3299-3540

Resumo: Estre trabalho surge a partir de incômodos de seus autores acerca do ensino de literatura e das discussões concernentes a esse domínio, sobretudo referente à exclusão da cultura de grupos subalternizados nos espaços educacionais. Nossa intenção é ampliar o debate sobre o impacto da colonialidade dos saberes no campo da educação e, mais especificamente, no contexto de ensino de literatura. Ao longo da discussão, temas como multiculturalismo, interculturalidade, cânone literário e formação de professores serão agenciados para fundamentar uma proposta de ensino de literatura estruturada pela diversidade cultural que compõe a sociedade, construída com os sujeitos subarternizados e incompatível com preconceitos étnicos-raciais, homofóbicos, misóginos e classistas. Apenas a partir dessas transformações, será possível pensar o ensino de literatura como processo educativo de inclusão e democratização cultural.

Palavras-chave: ensino de literatura; educação básica; decolonialidade.

Abstract: This work emerges from some discomfort shared by its authors regarding the teaching of literature and the discussions about this domain, especially related to the culture exclusion of some subalternized groups from educational spaces. Our intention is to expand the debate on the coloniality of knowledge impact in the field of education and, more specifically, in the context of teaching literature. In the course of the discussion, themes such as multiculturalism, interculturality, literature canon, and teacher education will be arranged to support a proposal for teaching literature structured by the cultural diversity in which society is set, built along with subarternized subjects and incompatible with ethnic-racial, homophobic, misogynist and classist prejudice. Only after these transformations, it will be possible to think about teaching literature as an educational process of cultural inclusion and democratization.

Keywords: literature teaching; basic education; decoloniality. 
Quem de nós aqui ainda se permite acreditar que os esforços para retomarmos o futuro podem ser particulares ou individuais? Quem aqui ainda se permite acreditar que a busca pela libertação pode ser incumbência única e exclusiva de uma só raça, ou um só sexo, uma idade, uma religião ou classe? Revolução não é algo que aconteça de uma vez e pronto. Revolução é se atentar cada vez mais para as mínimas oportunidades de promover mudanças verdadeiras nas relações estabelecidas e ultrapassadas; é, por exemplo, aprender a abordar com respeito as diferenças que há entre nós

(LORDE, 2019, p. 177).

\section{Introdução}

Antes de iniciarmos a problematização do conceito de decolonialidade, a fim de enquadrar o debate sobre o ensino de literatura, faz-se necessário explicitar os estímulos pessoais e acadêmicos para o desenvolvimento dessa reflexão. O primeiro estímulo resulta do incômodo com os usos da noção de cânone literário no contexto da educação básica. Desde a nossa formação inicial, sentíamos um desconforto com a ausência de autores negros, indígenas, LGBTQI, pertencentes às classes sociais menos favorecidas, entre outros, enfim, textos escritos pelos sujeitos subalternizados. Mesmo durante a formação universitária, poucos foram os autores e obras que retratavam realidades e pensamentos desses sujeitos. Hoje, como professores formadores de outros docentes, nos incomoda a resistência - velada ou explícita - que algumas instituições educacionais apresentam em trabalhar obras de escritores que fogem ao padrão excludente do cânone reconhecido tradicionalmente. Ainda que trabalhadas como objeto de ensino, muitas vezes impera a perspectiva estruturalista e a postura apreensiva e desconfortável, quase em caráter de concessão.

Outro incômodo decorre do modo como os estudos em ensino de literaturas muitas vezes abordam essa temática. Entendemos que muitos estudiosos buscam repensar os modos de se ensinar literatura, mas grande parte das pesquisas são reproduções de modelos e pensamentos que não dialogam mais com a realidade dos alunos brasileiros ou não se propõem a repensar o sistema educacional como um todo. Desde a Constituição de 1988 no Brasil, a escola foi "aberta para todos", mas de nada adianta incluir fisicamente os sujeitos à margem do sistema escolar e esperar que eles sejam proficientes nas mais variadas disciplinas se o próprio sistema escolar não 
for repensado, indisciplinado, reconstruído a partir dos sujeitos a quem ele deve acolher, aqueles que o sistema escolar contribui, muitas vezes, para marginalizar: sujeitos negros, das comunidades indígenas, LGBTQIs, mulheres, trabalhadores, entre outros.

Esses pontos a que chamamos incômodos e que viemos ao longo de anos, se não de todo nosso percurso pela educação formal, ruminando com muito desconforto guiam o propósito deste trabalho que é pensar um ensino de literatura que seja anti-racista, anti-homofóbico, anti-misoginia, contra preconceito às populações indígenas e às classes trabalhadoras, à população do campo, etc. Para tanto, queremos pensar e propor um ensino em que os sujeitos subalternizados sejam protagonistas, no qual se vejam incluídos não apenas através de documentos oficiais que mascaram todos esses preconceitos, invisibilizando parte da população do seu país, e sim através de práticas pedagógicas transgressoras, para lembrar bell hooks, ou libertadoras, para lembrar Paulo Freire.

O conceito que envolve nossa posição ética e política diante dessas questões e nos permite pensar esse tipo de educação é o de decolonialidade, uma vez que se trata de uma noção elaborada, sobretudo, por pensadores latino-americanos (mas também por pensadores de outros países do cone sul) que se concentram em analisar crítica e profundamente como a colonialidade europeia se impôs nas estruturas de poder na América Latina, nos modos de saber, ser e pensar dos povos dos países latino-americanos, desvendando a produção de conhecimento de uma episteme principalmente eurocêntrica e da América do Norte. A decolonialidade configura-se, pois, enquanto potência para se refletir e modificar estruturas fixas no que diz respeito ao ensino de literaturas, atuando, portanto, na perspectiva crítica da educação.

Assumimos, portanto, inteira concordância com o argumento Audre Lorde que abre nosso trabalho em relação à necessidade de pensarmos coletivamente para construirmos uma educação e uma sociedade liberta em que todos possam "aprender a abordar com respeito as diferenças que há entre nós”, que sejam vistos, representados, respeitados em suas diferenças. Para tanto, é necessário dar continuidade a trabalhos de pensadores que viam a educação enquanto prática libertadora, revolucionária. Precisamos, mesmo enfrentando adversidades e com maior lentidão do que desejamos, aproveitar as mínimas oportunidades para "promover mudanças verdadeiras nas relações estabelecidas e ultrapassadas". 


\section{A decolonialidade}

No final dos anos 1990, intelectuais latino-americanos de distintas nacionalidades e atuantes em diferentes universidades do continente americano constituíram o chamado grupo Modernidade/Colonialidade (M/C). Conforme Luciana Ballestrin (2013), o coletivo M/C realizou um movimento fundamental para o que ela nomeia de renovação crítica e utópica das Ciências Sociais da América Latina no século XXI. Assumindo variadas influências, esse grupo faz releituras históricas e problematiza questões referentes ao continente. Há, pois, uma defesa da "opção decolonial' - epistêmica, teórica e política - para compreender e atuar no mundo, marcado pela permanência da colonialidade global nos diferentes níveis da vida pessoal e coletiva" (BALLESTRIN, 2013, p. 89).

O grupo M/C se constituiu após o rompimento dos Estudos Subalternos Latino-americanos, os quais foram inspirados no grupo sulasiático de Estudos Subalternos, founding statment. O chamado grupo dos Estudos Subalternos Latino-americanos inseriu a América Latina nos chamados estudos pós-coloniais. No entanto, alguns intelectuais que posteriormente serão importantes para a formação do M/C, assim como para os estudos decoloniais, como Walter Mignolo, já demonstravam descontentamento com essa assunção de tais estudos pelos intelectuais do continente americano, uma vez que as teses dos teóricos do Grupo de Estudos Subalternos não deveriam ser simplesmente replicadas e traduzidas para o caso da América Latina (BALLESTRN, 2013). Nota-se que, já de partida, havia um desejo nascente de produzir conhecimentos que dessem conta especificamente das particularidades latino-americanas, sobretudo, de acordo com Ballestrin (2013), quando Mignolo aponta certo "imperialismo" dos Estudos Culturais, Pós-coloniais e Subalternos, por não terem rompido adequadamente com pensamentos e autores eurocêntricos. Ballestrin (2013) destaca que, para Mignolo, o grupo latino não deveria se espelhar na resposta indiana ao colonialismo, pois a trajetória de dominação e resistência da América Latina estava oculta no debate sendo que, para o desenvolvimento do capitalismo mundial, a história do continente foi peculiar, sofrendo primeiro a violência do esquema colonial/imperial moderno. "Além disso, os latino-americanos migrantes possuem outras relações de colonialidade por parte do novo império estadunidense - ele mesmo tendo sido uma colônia nas Américas" (BALLESTRIN, 2013, p. 96). 
Em 1998, ocorrem os primeiros encontros entre os membros que formariam posteriormente o Grupo Modernidade/Colonialidade, e o Grupo de Estudos Subalternos se desfaz devido a divergências teóricas (BALLESTRIN, 2013). O grupo M/C foi sendo construído aos poucos a partir de vários seminários, diálogos e publicações, e no ano 2000 foi lançada uma das mais importantes publicações coletivas do M/C que é La colonialidad del saber: eurocentrismo y ciências sociales.

A partir do M/C é forjada a ideia de decolonialidade, dentro da qual dois conceitos - apresentados pelo argentino Aníbal Quijano são fundamentais: "colonialidade do poder" e "modernidade". Para compreendê-los melhor é necessário escutar o que nos diz Quijano (2005): a América constitui-se como a primeira ideia de identidade da modernidade, sendo o primeiro espaço/tempo de um padrão de poder de vocação mundial. Dois eixos históricos convergiram e estabeleceram-se como eixos fundamentais de um novo padrão de poder: "por um lado, a codificação das diferenças entre conquistadores e conquistados na ideia de raça, ou seja, uma supostamente distinta estrutura biológica que situava a uns em situação natural de inferioridade em relação a outros" e "por outro lado, a articulação de todas as formas históricas de controle do trabalho, de seus recursos e de seus produtos, em torno do capital e do mercado mundial" (QUIJANO, 2005, p. 107).

Quijano postula que a ideia de raça, em seu sentido moderno, não tem nenhuma história conhecida antes da América, sendo construída como referência a supostas diferenças de estrutura biológica entre conquistadores e conquistados. Por sua vez, as relações sociais fundadas nessas diferenças produziram identidades sociais novas na América, tais como a de índios, negros e mestiços, também redefinindo outras. Raça e identidade racial foram estabelecidas, portanto, como instrumento de classificação social da população. Nos termos do autor, "Os dominantes chamaram a si mesmos de brancos" (QUIJANO, 2005, p. 107). Assim, a ideia de raça foi uma maneira de dar legitimidade às relações de dominação impostas pelo colonialismo, tornandose mesmo uma condição necessária para a existência da colonialidade do poder, dando início ao que modernamente conhecemos como racismo, ou seja, uma raça julgando-se superior às outras em razão de uma suposta superioridade em termos de língua, cultura e sistemas de conhecimento.

A constituição da Europa enquanto identidade teria se dado depois da descoberta da América, tendo a expansão colonialista para o 
resto do mundo conduzido à formação da perspectiva eurocêntrica do conhecimento, de modo que

os povos conquistados e dominados foram postos numa situação natural de inferioridade, e consequentemente também seus traços fenotípicos, bem como suas descobertas mentais e culturais. Desse modo, raça converteu-se no primeiro critério fundamental para a distribuição da população mundial (QUIJANO, 2005, p. 108).

Produziram-se, então, novas identidades sobre a ideia de raça e as mesmas foram associadas aos papéis e lugares nas estruturas de trabalho, impondo-se uma sistemática divisão racial do trabalho. Dessa forma,

a classificação racial da população e a velha associação das novas identidades raciais dos colonizados com as formas de controle não pago, não assalariado, do trabalho, desenvolveu entre os europeus ou brancos a específica percepção de que o trabalho pago era privilégio dos brancos. A inferioridade racial dos colonizados implicava que não eram dignos do pagamento de salário. Estavam naturalmente obrigados a trabalhar em benefício de seus amos (QUIJANO, 2005, p. 110).

Enquanto centro do capitalismo mundial, a Europa não somente controlava o mercado do mundo todo como também impunha seu domínio colonial sobre todas as populações e regiões do planeta. Foram atribuídas novas identidades sociais (índios, negros, azeitonados, amarelos, brancos e mestiços) e geoculturais (americana, africana, oriental, ocidental e europeia) às populações do mundo. "Desse modo, depois da América e da Europa, foram estabelecidas África, Ásia e eventualmente Oceania. Na produção dessas novas identidades, a colonialidade do novo padrão de poder foi, sem dúvida, uma das mais ativas determinações" (QUIJANO, 2005, p. 110. Grifo nosso.).

Os europeus imaginaram ser a culminação de uma trajetória civilizatória, pensando-se como os modernos da humanidade e de sua história, criadores e portadores da modernidade. A elaboração intelectual do processo de modernidade chegou a produzir perspectivas de conhecimento que demonstram o caráter colonial/moderno, capitalista e eurocentrado de maneira mundial (QUIJANO, 2005). O eurocentrismo teve como objetivo homogeneizar as formas básicas de existência social de todas as populações e seus domínios o que implicou em estratégias para controle dos poderes, dos 
saberes, dos modos de ser e das sexualidades das populações colonizadas. "Quer dizer, as mudanças ocorrem em todos os âmbitos da existência social dos povos, e portanto de seus membros individuais, tanto na dimensão material como na dimensão subjetiva dessas relações" (QUIJANO, 2005, p. 114).

Para Maria Lugones (2020), Quijano compreende, pois, que o poder se estrutura em relações de dominação, exploração e conflito entre poderes que disputam o controle do sexo, do trabalho, da autoridade coletiva e da subjetividade/intersubjetividade, assim como seus recursos e produtos. $\mathrm{O}$ poder capitalista eurocêntrico e global estaria, assim, organizado sobre os eixos da colonialidade do poder e da modernidade, os quais ordenam as disputas pelo controle de todas as áreas da vida. A colonialidade é, portanto, "um dos eixos do sistema de poder e, como tal, atravessa o controle do acesso ao sexo, a autoridade coletiva, o trabalho e a subjetividade/ intersubjetividade, e atravessa também a produção de conhecimento, a partir do próprio interior dessas relações intersubjetivas" (LUGONES, 2020, p. 57). Todas e quaisquer formas de controle da subjetividade, do sexo, da autoridade e do trabalho estão em conexão com a colonialidade.

Talvez aqui seja importante destacarmos que colonialismo e colonialidade não são conceitos correlatos. Para Maldonado-Torres (2007), o colonialismo relaciona-se à dominação política e econômica em que a soberania de um povo reside no poder de outra nação, constituindo-a em um império. Já a ideia de colonialidade,

se refere a um padrão de poder que emergiu como resultado do colonialismo moderno, mas em vez de estar limitado a uma relação formal de poder entre os povos ou nações, mais bem se refere a forma como o trabalho, a autoridade e as relações intersubjetivas se articulam entre si, através do mercado mundial e da ideia de raça (MALDONADO-TORRES, 2017, p. 131). ${ }^{1}$

Mesmo que o colonialismo preceda à colonialidade, esta sobrevive a ele se mantendo viva através de vários elementos, tais como nos manuais de

\footnotetext{
${ }^{1}$ Tradução nossa de: “[...] la colonialidad se refiere a un patrón de poder que emergió como resultado del colonialismo moderno, pero que en vez de estar limitado a una relación formal de poder entre dos pueblos o naciones, más bien se refiere a la forma como el trabajo, el conocimiento, la autoridade y las relaciones intersubjetivas se articulan entre sí, a través del mercado capitalista mundial y de la idea de raza".
} 
aprendizagem (livros didáticos, entre outros), nas normas para produção de trabalhos acadêmicos, na cultura comum, na autoimagem dos povos e nas aspirações dos sujeitos, para ficarmos em alguns exemplos, ou seja, "respiramos a colonialidade na modernidade cotidianamente" (MALDONADOTORRES, 2007, p. 131). ${ }^{2}$ A colonialidade se estabeleceu através de formas de subordinação e dominação centrais para se manter e justificar a dominação sobre os povos não-europeus. Com a colonialidade, os modos de poder, de saber, de ser dos povos colonizados são simplesmente silenciados e busca-se impor os valores europeus, norte-cêntricos, como únicos e universais.

Como nos diz Lugones (2020), até mesmo diferenças de gênero foram introduzidas onde antes não existiam, de forma que a pluralidade fosse substituída por um ser supremo masculino. A autora destaca que em sociedades indígenas presentes na América, o gênero não era entendido fundamentalmente em termos biológicos e a maioria dos indivíduos se encaixava em papeis de gênero tribais baseados na sua propensão, inclinação e temperamento. Foi o colonizador quem cooptou os homens colonizados para ocuparem os papeis patriarcais. Não quer dizer que não houvesse relações patriarcais em muitas sociedades colonizadas, mas que havia modos muito plurais de relação no domínio do que se entende por gênero ${ }^{3}$ e que foram, paulatinamente, sendo substituídos por aqueles impostos a partir do eurocentrismo e com ajuda de esferas de poder como Estado e Igreja. Ao citar Allen, Lugones destaca que

a heterossexualidade característica da construção colonial/ moderna das relações de gênero é produzida/construída miticamente. Mas a heterossexualidade não está apenas biologizada de maneira fictícia, ela também é obrigatória e permeia toda a colonialidade do gênero [...]. Nesse sentido, o capitalismo eurocêntrico global é heterossexual (LUGONES, 2020, p. 71).

Diante dessas reflexões, é importante enfatizar que as estruturas misóginas e homofóbicas, por exemplo, não eram "inatas" aos seres humanos, como postulava a cultura europeia. Lugones (2020) informa que

\footnotetext{
2 Tradução nossa de: "En un sentido, respiramos la colonialidad en la modernidad cotidianamente"

${ }^{3} \mathrm{O}$ que não deixa de ser um entendimento atravessado pelo eurocentrismo.
} 
muitas tribos americanas reconheciam a homossexualidade masculina e feminina de maneira positiva. É importante, também, relacionar a questão de gênero com a ideia de raça, uma vez que as fêmeas racializadas, tidas como inferiores, "foram transformadas de animais a diferentes versões de mulher - tantas quantas foram necessárias para os processos de capitalismo eurocêntrico global" (LUGONES, 2020, p. 74). A autora ainda destaca que

a violação heterossexual das mulheres índias ou de escravas africanas coexistiu com o concubinato, bem como a imposição do entendimento heterossexual das relações de gênero entre os colonizados - quando isso foi conveniente e favorável ao capitalismo eurocêntrico global e à dominação heterossexual das mulheres brancas" (LUGONES, 2020, p. 74).

Há diferentes implicações que podem ser feitas a partir da ideia de colonialidade do poder, uma vez que todas as relações humanas são pautadas de algum modo pelo poder e, como vimos, no caso da colonização, ele foi imposto de maneira brutal aos povos colonizados, os quais tiveram suas histórias, subjetividades e culturas silenciadas. Uma das implicações imbricadas na colonialidade do poder que nos chama atenção é um terceiro tipo de colonialidade (lembrando que todos se interpenetram): a do ser, conceito criado por Nelson Maldonado-Torres (2007). De acordo com o pesquisador, a concepção subjacente à colonialidade do ser relaciona-se à epistemologia e às tarefas gerais implicadas na produção de conhecimento para a reprodução dos regimes de pensamento coloniais, referindo-se às experiências vividas da colonização e seus impactos na linguagem.

As expressões primárias da colonialidade do ser, para MaldonadoTorres (2007), são a "invisibilização" e a "desumanização". Esses aspectos acabam por produzir uma exceção na ordem do ser, no sentido de que se produz o humano e seu mundo em oposição ao não-ser humano e a um mundo inumano. A alteridade humana é violada, sujeitos são apagados, tidos como abjetos, aproximados, por fim, à ideia de natureza a ser conquistada e dominada. Foi exatamente o que ocorreu com as populações indígenas e a negra da diáspora americana: ambas sofreram inúmeros processos de exclusão, silenciamento, escravização e apagamento (e ainda sofrem de muitas maneiras, lutando para serem respeitadas e reconhecidas). Como ressalta o estudioso, a colonialidade do ser se relaciona à produção da 
linha de cor (a ideia de raça) em suas diferentes expressões e dimensões, produzindo a diferença ontológica colonial.

No caso das mulheres amefricanas e ameríndias, por exemplo, o apagamento vem em dobro, como nos diz Lélia Gonzales (2020). A estudiosa brasileira argumenta que essas mulheres carregam o duplo caráter de sua condição biológica (racial e sexual), fazendo com que elas sejam mais oprimidas e exploradas em um estado capitalista patriarcalracista dependente. Esse sistema acaba por transformar "as diferenças em desigualdades" e "a discriminação que elas sofrem assumem um caráter triplo: dada a sua posição de classe, ameríndias e amefricanas fazem parte, em sua maioria, do proletariado afro-latino-americano" (GONZALES, 2020, p. 46). Não podemos deixar de ressaltar também que, em um país como o Brasil, em que LGBTQIs são sistematicamente violentados, as pessoas nomeadas por essa sigla são consideradas abjetas e, quanto mais se distanciam do que hegemonicamente é posto como homem-mulhercis-padrão-branco e das classes sociais com maior poder aquisitivo, mais violência a elas é dirigida, ou seja, também sofrem esse triplo caráter de discriminação: o sexual, o de classe e o de raça.

Outra importante implicação da colonialidade do poder que desejamos evidenciar é a colonialidade dos saberes (assim, no plural). Interessa-nos desenvolver uma reflexão sobre essa colonialidade dos saberes recorrendo, para isso, às análises de Carlos Porto-Gonçalves (2005), extremante instigantes. Ele nos revela que a colonialidade, através do eurocentrismo, produziu uma geopolítica do conhecimento, impondo aos demais povos a crença de que a ciência seria uma invenção moderna dos povos europeus. Essa proposição implica, em consequência na desconsideração dos milenares conhecimentos filosóficos, artístico-literários, e na ciência agrícola produzidos na África, na América e na Ásia, entre muitos outros modos de saber. Segundo nos diz Aníbal Quijano (2007), esse conhecimento foi, por seu caráter e origem eurocêntrico, denominado "racional", imposto ao conjunto do mundo capitalista como única racionalidade válida e emblema da modernidade. Quijano postula que a revolta contra a perspectiva e o modo eurocêntrico de produzir conhecimento nunca esteve exatamente ausente, em particular na América Latina, configurando justamente o que vem sendo denominado como decolonialidade.

Segundo nos diz Walter Mignolo (2007), o pensamento decolonial emergiu da própria fundação da ideia de colonialidade/modernidade, 
como contrapartida a este último, tendo ocorrido nas Américas a partir dos pensamentos indígena e afro-americanos, encontrando ecos na África e Ásia, traçando uma genealogia própria após o fim da Guerra Fria. O estudioso argentino ainda nos revela que

a decolonialidade é, então, a energia que não se deixa manejar pela lógica da colonialidade nem crê em contos de fadas da retórica da modernidade. Se a decolonialidade tem uma variada gama de manifestações - algumas não desejáveis, com as que hoje Washington descreve como "terroristas" - o pensamento decolonial é, então, o pensamento que se desprende e se abre [...] encoberto pela racionalidade moderna, montado e fechado nas categorias do grego e do latim e das seis línguas imperiais modernas (MIGNOLO, 2007, p. 27). ${ }^{4}$

Essa abertura assinalada por Mignolo (2007) é profícua quando a entendemos como uma nova possibilidade de construção e resgate de saberes produzidos por povos e sujeitos subalternizados, os quais agora buscam se colocar como protagonistas de suas próprias histórias, fugindo dos pensamentos duais impostos pelo eurocentrismo (bem/mal; homem/ mulher; ocidente/oriente, etc.), e incluindo (visibilizando) muitos outros sujeitos que foram massacrados, física e culturalmente, ao longo dos anos. Por isso, a nosso ver, trabalhar com a decolonialidade enquanto constructo ético e teórico é produtivo, desde que considerada como potência para se refletir e modificar estruturas fixas. A decolonialidade nos propicia incorporar o conhecimento produzido fora dos centros hegemônicos, os assujeitados no processo de colonialidade (negros, mulheres, indígenas, LGBTQIs, populações das classes trabalhadoras, dentre outros), de forma a buscar a reestruturação do sistema, com vistas a torná-lo cada vez mais aberto, sem que haja hierarquização de saberes, de histórias, de línguas, de modos de ser. É, pois, um desafio. O mérito dessa propositiva assume

\footnotetext{
${ }^{4}$ Tradução nossa de: "La decolonialidad es, entonces, la energía que no se deja manejar por la lógica de la colonialidad, ni se cree los cuentos de hadas de la retórica de la modernidad. Si la decolonialidad tiene una variada gama de manifestaciones -algunas no deseables, como las que hoy Washington describe como "terroristas"-, el pensamento decolonial es, entonces, el pensamiento que se desprende y se abre (de ahí "desprendimiento y apertura" en el título de este trabajo), encubierto por la racionalidad moderna, montado y encerrado en las categorías del griego y del latín y de las seis lenguas imperiales europeas modernas."
} 
importância ainda maior quando compreendemos, junto com PortoGonçalves, que além das desigualdades e injustiças sociais provenientes do legado colonialista e imperialista “... há um legado epistemológico do eurocentrismo que nos impede de compreender o mundo a partir do próprio mundo em que vivemos e das epistemes que lhes são próprias" (2005, p. 3).

Acreditamos, portanto, ser de grande relevância investigar os desdobramentos da colonialidade do saber a que estamos ainda hoje expostos, e dos quais muitos de nós não têm consciência, bem como utilizar essa abertura para impulsionar novas pesquisas e revisitações de trabalhos elaborados por pensadores latino-americanos/do cone sul do mundo, uma vez que a lógica da colonialidade tende a atribuir valores ideológicos aos lugares de pesquisa, reforçando estruturas desiguais de participação na construção de conhecimentos.

\section{Um ensino decolonial de literatura}

Quando pensamos na produção acadêmica brasileira e no ensino de um modo geral, não podemos desvincular esses dois elementos da colonialidade do poder na sua forma de colonialidade do saber. Apenas com a Constituição Federal de 1988, a educação passa a figurar oficialmente como direito de todos e não mais apenas como uma política assistencialista do Estado. Até essa data, havia já regulamentado o direito de todos à escolarização, mas a gratuidade era restrita a grupos que comprovassem insuficiência de recursos, o que mantém, na prática, a exclusão. A nova referência legal é anunciada pelo artigo 205 da Carta, que estabelece:

A educação, direito de todos e dever do Estado e da família, será promovida e incentivada com a colaboração da sociedade, visando ao pleno desenvolvimento da pessoa, seu preparo para o exercício da cidadania e sua qualificação para o trabalho. (BRASIL, 1988)

Até a promulgação deste documento oficial, o ensino era oferecido, de fato, somente a uma parcela da população brasileira, a elite econômica das diferentes regiões do país que, por sua vez, era composta pelos detentores do poder político. Com a promulgação da Constituição, a escola passa a ser obrigada a acolher, paulatinamente, todas as parcelas da população do país, até que o ensino público fosse oferecido a todos. Digamos que esse ensino 
para todos é ainda hoje um mito, pois uma parcela tida como subalterna de nossa sociedade continua excluída do sistema escolar, em razão de vários fatores, dentre os quais enumeraremos alguns: racismo, LGBTQIfobia, misoginia, preconceito contra populações indígenas e do campo, por exemplo. Portanto, não basta garantir o acesso à escola, mas oferecer condições de permanência aos grupos antes excluídos e que continuam à margem dos processos, pela negação de suas cosmogonias.

Se o reconhecimento da educação como direito fundamental de todos e dever do Estado é um princípio constitucional recente, a planificação desse direito na legislação educacional representa uma conquista ainda mais contemporânea, que só se concretizou como resultado de lutas e reivindicações de movimentos populares. A partir da Lei das Diretrizes e Bases da Educação Nacional (BRASIL, 1996), a diferença cultural passa a ser mencionada como legítima, contrapondo-se à postura assimilacionista e tutelar do Estado frente aos grupos subalternizados. Em relação aos marcos legais, apenas em 2003 (BRASIL, 2003) institui-se a lei que torna obrigatório o ensino de cultura afro-brasileira nas escolas públicas e privadas da educação básica, sendo ampliada em 2008 para contemplar a cultura e história indígenas (BRASIL, 2008); em 2010 são estabelecidas as Diretrizes Operacionais para a Educação Básica nas Escolas do Campo e, somente em 2012, as Diretrizes Curriculares Nacionais para a Educação Escolar Indígena (BRASIL, 2021). Questões relacionadas a gênero e diversidade sexual, incluindo os direitos da mulher, são ainda mais recentes e limitamse ao âmbito dos direitos humanos e da saúde, não sendo, ainda, alvo de políticas educacionais.

É preciso analisar, inicialmente, o que significou essa "abertura" da escola a todos os cidadãos, independentemente de classe social ou de pertencimentos culturais. Apesar do pouco distanciamento temporal, já é possível avaliar que as determinações legais não ultrapassaram a letra da lei, tendo efeito insuficiente para o estabelecimento de uma inclusão real e efetiva. Diante disso, perguntamo-nos: de que forma o colonialismo pode estar relacionado a esta conjuntura? Uma possível resposta a esse questionamento aponta para a política educacional "multicultural" que, ao menos na superfície discursiva, reconhece a "diversidade", como é possível perceber desde os Parâmetros Curriculares Nacionais (PCNs, 1996) até a Base Nacional Comum Curricular (BNCC, 2018). Nestes documentos, nota-se uma frequência de proposições que giram em torno de elementos 
como "preconceito linguístico", "variedade de gêneros discursivos", abertura para "culturas indígena e afro-brasileira", "literatura não-canônica", “cultura juvenil” e outros. No entanto, a nosso ver, essa é apenas uma estratégia retórica e ideológica que se mascara de inclusiva. A manobra discursiva pressuposta nestas iniciativas fica evidente na formulação da versão homologada da BNCC, que desenvolve uma concepção seletiva de diversidade, desconsiderando o debate no campo da cultura e da sociologia e apagando as diversidades que não interessam ao projeto político de educação que orienta o documento. Assim, a Base vale-se de complementos vagos e distensos para o termo diversidade, como "diversidade humana", "diversidade linguística", "diversidade de formação e vivências", "diversidade de opiniões", dentre outros, mas omite questões como identidade de gênero, racismo e classe social.

Nesse sentido, como aponta Catherine Walsh (2009, p. 8), a política "multicultural" é apenas uma estratégia do mundo moderno colonial que pretende incluir os anteriormente deixados de fora dentro de um modelo globalizado de sociedade que, na verdade, é regido por interesses mercadológicos. A estudiosa ressalta que essa estratégia política não busca nem se interessa por transformar as estruturas sociais racializadas, tendo como objetivo administrar a diversidade diante do que é visto como "perigo de radicalização de imaginários e agenciamentos". Ou seja, seria uma apropriação das culturas subalternizadas pelo neoliberalismo não com fins de incluir, senão de controlar os possíveis sujeitos potencialmente rebeldes. Para Walsh, mesmo quando está presente no discurso, o dito reconhecimento e respeito à diversidade cultural, sexual, linguística passa a ser uma nova estratégia de dominação que ofusca e mantém a diferença colonial. O discurso "inclusivo" do multiculturalismo e da interculturalidade se vende como uma ferramenta a serviço de sociedades mais equitativas e igualitárias quando, na verdade, há o desejo de controlar o conflito étnico e manter a estabilidade social para impulsionar os imperativos econômicos do neoliberalismo, da acumulação capitalista.

Os grupos historicamente excluídos são, na verdade, ludibriados, visto que, na prática, permanecem silenciados. Os sujeitos que detêm o poder (político, econômico ou simbólico) não renunciam a suas prerrogativas de classe, nem ao monopólio hegemônico de suas culturas, empenhando-se para a manutenção dos saberes privilegiados nas mãos de poucos, justamente aqueles pertencentes às classes ou grupos sociais privilegiados. No caso 
brasileiro, não é preciso nos afastarmos muito no curso da história para demonstrarmos esse movimento ideológico. Para citar um exemplo recente, temos a Emenda Constitucional 96, aprovada em 2016 sob o comando do então presidente Michel Temer, instituindo o congelamento de verbas para a educação e para a saúde por vinte anos. Soma-se a isso o projeto "Escola sem partido", apelidado por alguns de "Escola da mordaça", que busca monitorar a atuação dos professores, coagindo aqueles que tratem em suas aulas de questões referentes a gênero, raça e fatos históricos, sendo acusados de uma suposta interpretação ideológica à esquerda. E são apenas dois exemplos de um cenário educacional contemporâneo profundamente orientado pelos ideais do conservadorismo e do neoliberalismo. Enquanto as estruturas, os dispositivos e os mecanismos de poder institucional que mantêm os padrões de desigualdade não forem desconstruídos, repensados e refeitos, considerando, de fato, aqueles que foram sistematicamente omitidos da história, - inclusive com a participação autoral, neste processo, dos sujeitos até aqui invisibilizados -, acreditamos que não alcançaremos equidade, tampouco democracia.

Como contraponto ao que nomeia de interculturalidade funcional, Catherine Walsh (2009) defende a concepção de interculturalidade crítica, modelo que questionaria a abordagem funcional vigente, respondendo aos interesses e necessidades das instituições sociais: trata-se da construção de e a partir das pessoas que sofreram na história com a subalternização. Seria, pois, a interculturalidade crítica um processo de reexistência, para um outro imaginário, outra maneira de conviver, de viver em sociedade. Os sujeitos que foram subalternizados, que sofrem com racismo, preconceitos de ordem diversa, apagamento de suas culturas e identidades precisam de espaços de resistência para que existam plenamente.

Não pensemos que esse processo seja algo novo, “... uma agenda descolonizadora já está presente nos processos de resistência e reexistência das populações negras, indígenas e populações brasileiras e do sul global ao longo da chamada modernidade/colonialidade" (BERNARDINOCOSTA et all, 2019, p. 19). Destacamos que também encontramos esses processos nas populações LGBTQIs, nos diversos movimentos feministas, nos coletivos das populações do campo e demais movimentos populares, como o MST e o MTST, ${ }^{5}$ de modo a que esses sujeitos subalternizados, a

\footnotetext{
${ }^{5}$ Referimo-nos ao Movimento dos Trabalhadores Rurais Sem Terra e ao Movimento dos
} 
partir da atitude decolonial, emergem como pensadores, criadores, ativistas "a fim de construir um mundo novo onde outros mundos também sejam possíveis” (BERNARDINO-COSTA et al., 2019, p. 19).

Numa leitura decolonial do campo de ensino de literatura, especificamente, pode se configurar como um início revolucionário o próprio ato de ouvir os sujeitos subalternizados que foram por séculos desautorizados nos rituais de leitura escolares (e não só). Para tanto, há que se considerar que a determinação do cânone e também a atuação da crítica literária, durante séculos, se pautou em modelos e critérios eurocêntricos para decidir o que deve ou não ser visto como literatura, a partir da ótica de uma série de fatores históricos mobilizados seletivamente. Como resultado sintomático, notamos que a considerada "alta literatura" brasileira, que tende a constituir os acervos escolares, é composta, em sua maioria, por autores brancos, heterossexuais, de classe média ou classe alta, desprestigiando produções de autores(as) negros(as), LGBTQIs, indígenas, das camadas populares, consideradas, indiretamente ou não, como "o outro", a "não literatura". Evidentemente, não se omite aqui os processos complexos que condicionam a filiação de uma obra a uma tradição cultural, justificando sua permanência no horizonte de leitura de gerações subsequentes. É preciso levar em consideração duas acepções importantes da noção de cânone literário: uma que a define como produções verbais que ditam normas estilísticas e estéticas em determinada época, cujo mérito artístico é determinado pela crítica especializada, e outra que a associa à ideia de "clássicos", obras representativas de uma conformação social, historicamente marcada, que continuam atraindo leitores, independentemente de normas estéticas preestabelecidas. Portanto, para nossos propósitos, não se trata de propor a renúncia ao cânone estabelecido, em nome das literaturas consideradas periféricas, mas de reivindicar a convivência, em particular no espaço escolar, das múltiplas manifestações culturais representativas da sociedade. Assim, assumimos a compreensão da leitura como ferramenta para a plena democratização cultural, possibilitando a distribuição equitativa dos bens simbólicos. Dito de modo preciso:

A leitura literária democratiza o ser humano porque mostra o homem e a sociedade em sua diversidade e complexidade,

Trabalhadores Sem Teto, respectivamente. 
e assim nos torna mais compreensivos, mais tolerantes compreensão e tolerância são condições essenciais para a democracia cultural (SOARES, 2008, p. 31)

Neste sentido, ao se considerar o ensino na educação básica brasileira é preciso levar em conta os contextos sociopolíticos dos sujeitos que a compõem. Desde a era Vargas, uma série de reformas educacionais orientadas para a massificação do acesso ao ensino com o propósito de qualificar a mão de obra para a indústria modificou profundamente a configuração do ensino público, acarretando graves consequências como a ampliação do número de alunos por sala de aula e a precarização e intensificação do trabalho docente. Ao mesmo tempo, tais decisões políticas propiciaram o ingresso no meio escolar de grupos sociais antes situados à margem dos processos formais de educação, cuja cultura, hábitos, valores, crenças e saberes permaneciam excluídos dos conhecimentos validados pela instituição escolar. Por isso dizemos que a expansão do ensino no contexto brasileiro não promoveu a efetiva democratização da educação pública, visto que não atendeu às exigências éticas de reestruturação do sistema educacional para que este pudesse contemplar a diversidade sociocultural de maneira não hierárquica de seus novos atores.

Por si só, a chamada "cultura escolar" tende a impor um padrão universalizante aos objetos de conhecimento com os quais constrói os currículos, desconsiderando as experiências culturais que fogem ao paradigma hegemônico. Esse modelo de escola acarreta uma série de desajustes identitários, favorecendo a baixa autoestima, o desinteresse e até a hostilidade dos alunos em relação à escola (CANDAU, 2013, p. 27). A abordagem intercultural crítica na educação, ao contrário, pressupõe o questionamento dessa suposta universalidade do conhecimento escolar, e, ao mesmo tempo, exige que se evite o relativismo absoluto que levaria à inversão dos modelos epistêmicos tidos como centrais e periféricos. Tal perspectiva funda-se no princípio da negociação de sentidos entre os espectros culturais e não na hierarquização a priori dos saberes. Além disso, impõe à prática docente a necessidade de

desvelar o caráter histórico e construído dos conhecimentos escolares e sua íntima relação com os contextos sociais em que são produzidos. Obriga-nos a repensar nossas escolhas, nossos modos de construir o currículo escolar e nossas categorias de análise da produção dos nossos alunos/as (CANDAU, 2013, p. 33) 
Portanto, o ensino de literatura na educação básica, especialmente na rede pública, não pode corroborar para a neutralização das matrizes culturais que compõem o quadro de leitores em formação. Sobretudo neste contexto educacional, é indispensável que o professor de literatura assuma uma postura ética e política, a fim de desenvolver uma mediação de leitura que considere as realidades locais, as subjetividades dos leitores em formação e os sistemas de referência simbólica que os contorna.

Para além dessa condição elementar para um ensino crítico de literatura, outros paradigmas hegemônicos no campo precisam ser revisitados como, por exemplo, os modelos de teoria e crítica literária aplicados ao ensino, o papel do cânone na formação do leitor, a posição política do mediador de leitura e a supremacia dos parâmetros acadêmicos na legitimação das formas de convivência com o texto literário.

Numa discussão que põe em questão a colonialidade dos saberes, não se pode desconsiderar que a ascensão da teoria literária, especialmente a historicista, e o estabelecimento da crítica como disciplina universitária se deram a partir de moldes epistêmicos construídos sobre realidades históricas muito distintas, como podemos supor das abordagens do formalismo russo, do estruturalismo tcheco, do desconstrutivismo francês e da estética da recepção alemã, todas provenientes de potências historicamente colonizadoras e/ou imperialistas. Apenas a partir doa década de 1970, novas abordagens se contrapuseram aos modos de apreensão e crítica das obras literárias pautadas pela modernidade eurocentrada, dando origem aos chamados estudos Pós-Coloniais, que buscavam a "construção de epistemologias que apontam para outros paradigmas metodológicos [...] diferentes dos 'clássicos' na análise cultural e literária” (MATA, 2014, p. 31). Apesar disso, como dito anteriormente, a maioria dos pesquisadores deste grupo ainda permanecia, no âmbito dos estudos literários, subserviente às construções teóricas de estudiosos europeus e norte-americanos, gerandose a necessidade de uma diferenciação mais evidente com a hegemonia das formas de conhecer do hemisfério norte.

Portanto, nossa proposta alinha-se com pressupostos mais exigentes em termos de autorias epistêmicas, no esforço de decolonizar o ensino de literatura e a determinação dos cânones escolares, na maior parte pautados por critérios estranhos à dinâmica histórica e cultural do país. Para Zilberman, a escola alimenta um círculo vicioso por meio do qual reproduz as hierarquias de poder simbólico próprias da sociedade, visto que, neste espaço institucional, 
leem-se boas obras já sacramentadas pela tradição e seus mecanismos de difusão, para que se forme o juízo elevado, aquele que, educado, dará preferência a criações de teor similar às que constituem a antologia, reforçando sua autoridade; e porque consistem em modelos de uso correto das virtualidades da linguagem verbal, cabendo imita-las, reproduzi-las, portanto (ZILBERMAN, 2012, p. 237).

Para a pesquisadora, a teoria literária se interessa pelo ato individual de leitura, mas evita o debate sobre a popularização de seu objeto, para além dos espaços institucionais. Com isso, "arrisca-se [...] a permanecer confinada, aumentando o fosso que separa a literatura [...] daquilo que the confere a existência e sentido: o público leitor, independentemente de suas raízes sociais" (ZILBERMAN, 2012, p. 248). Se a teorização em torno da literatura e o exercício da crítica servem ao interesse de amplificar os sentidos do texto literário, expandindo, igualmente, o escopo de seu efeito sobre a subjetividade do leitor, então o ensino não deve permanecer refém de uma vertente da crítica ou de uma teoria literária particular, com o risco de formatar a interpretação das obras com base em categorias preestabelecidas, tidas como universais.

Evidentemente, não sugerimos a negação das conquistas teóricas da tradição de estudos do campo literário. Ao contrário, a ideia é justamente tornar possível o convívio intercultural crítico que promova o diálogo de pontos de vista distintos e até mesmo antagônicos. Defendemos, portanto, o protagonismo do professor-mediador de leitura no sentido de apropriarse de conceitos e categorias analíticas a partir de uma perspectiva situada e política, informada pelo paradigma do contexto de leitura único e irrepetível, mediado pelos processos de ensino e aprendizagem. Uma postura como essa pode autorizar o uso, por parte dos alunos, de chaves de leitura reveladoras de dimensões sociais da obra apagadas ou desvalorizadas pela crítica autorizada. A projeção das identidades subalternizadas e a valorização dos seus modos de perceber e viver podem acionar modos de leitura que revelem, nas obras, relações ideológicas e de poder que refletem ou refratam as relações materiais objetivas.

A partir de uma leitura decolonializada, o sujeito leitor se realinha diante do texto literário, conquistando o direito de desempenhar outros papeis diante dele. Superando a limitação do papel de apreciador-fruidor convencionalmente priorizado pela escola -, o leitor passa a se posicionar 
como um sujeito consciente do lugar que ocupa na engrenagem do poder, atuando como um crítico dos produtos culturais que circulam no mercado simbólico, atravessado, este último, por interesses muitas vezes estranhos ao campo. O amadurecimento de uma postura leitora como esta pode acarretar a desmistificação da obra e promover a afirmação de subjetividades reprimidas por enquadramentos de leitura impositivos de rituais, humores e efeitos de sentido como se fossem os únicos válidos.

Para que o ensino de literatura na educação básica possa se concretizar no contexto de práticas emancipadoras, é fundamental que o mediador de leitura estabeleça condições - materiais, afetivas e dialógicas - para uma interação crítica e autêntica com o texto literário e com a versão de mundo que ele propõe. Neste ponto, torna-se imperativo discutir os pressupostos que orientam a formação de professores de literatura para a educação básica. Apesar da presença recente e compulsória de disciplinas que tratem das relações étnico-raciais nos cursos de graduação, o tratamento da literatura marginal, da literatura de apelo comercial ou da produção cultural e literária de grupos subalternizados ainda não parece ser sistemático. Aliás, além do catálogo nacional, as obras selecionadas para leitura e análise nos cursos de formação de professores são retiradas predominantemente da tradição literária europeia, especialmente a portuguesa, secundarizando a criação de autores indígenas ou latino-americanos, por exemplo.

Para além da determinação do escopo temático ou da filiação estilística das obras, sabemos que os conteúdos programáticos das disciplinas de formação literária nas licenciaturas em Letras pouco exigem em termos de ampliação e diversificação dos repertórios de leitura. A ênfase é dada, quase sempre, para a historiografia e crítica literária, orientadas, ambas, pelo cânone de cada época, em detrimento de um debate amplo sobre o ensino de literatura na educação básica, o que deveria ser atribuição prioritária de um curso de licenciatura em Letras. Aliás, poucas são as matrizes curriculares dos cursos de Letras (e mesmo de pedagogia) em que disciplinas específicas de ensino de literatura ou de literatura infanto-juvenil comparecem. Esta constatação revela o caráter bacharelesco das licenciaturas em Letras e, também, o descaso com uma formação inclusiva de leitores no espaço da educação básica brasileira. Como resultado, muitas vezes, o recém-formado professor não chega a se tornar leitor de literatura - pois não conseguiu estabelecer uma convivência afetiva com os "clássicos" - nem a constituir um acervo particular diversificado e amplo o suficiente para nortear as mediações que precisará fazer entre as 
subjetividades e pertencimentos variados de seus alunos, reproduzindo, apenas, as instruções que recebera da universidade.

\section{Considerações finais}

A discussão acerca do ensino de literatura que fizemos ao longo deste trabalho, por si só, apontam um problema estrutural-colonial, racial, de gênero e classe que necessita de transformação para que se construam condições distintas e realmente inclusivas. Essa transformação, que é política e cultural, não se limita a esferas sociais e culturais como também se relaciona aos campos do saber e do ser. Ao fazermos essa reflexão, temos que reconhecer, com Catherine Walsh (2009), que as estruturas em que se fundam a nossa escola e as práticas de ensino que ainda hoje se perpetuam possuem em si práticas de exclusão, negação e subalternização dos grupos e sujeitos racializados, caracterizando-se, pois, como práticas de desumanização e subordinação de conhecimentos, "que privilegiam uns em lugar de outros, naturalizando a diferença e ocultando as desigualdades que se estruturam e se mantêm em seu interior (WALSH, 2009, p. 11)". 'Dessas práticas queremos nos desvincular, buscando caminhos outros em que a desumanização, a hierarquização e o preconceito em todas as dimensões sejam problematizados e combatidos.

Para tanto, queremos pensar o ensino de literatura enquanto um campo crítico capaz de questionar a colonialidade por trás dos documentos oficiais, das políticas públicas de promoção da leitura, da escolha das obras, da formação de professores de literatura, dos currículos escolares e universitários, etc. Que seja um campo construído enquanto projeto questionador de ausências, trabalhando pela ampliação do próprio entendimento a respeito do que é o texto literário, e não simplesmente pela substituição de um padrão por outro. Aliás, que não haja "padrões" e sim espaço para as distintas vozes.

A partir do reconhecimento da literatura e do seu ensino como campos que posicionam grupos, práticas e pensamentos de maneira hierárquica, dentro de uma lógica moderna/colonial, racial, de gênero e de classe, é necessário enfrentar e transformar as estruturas das quais,

\footnotetext{
${ }^{6}$ Tradução nossa de: "[...] que privilegian algunos sobre otros, "naturalizando" la diferencia y ocultando las desigualdades que se estructuran y se mantienen a su interior".
} 
de uma forma ou de outra, também participamos. Precisamos propor novas ferramentas pedagógicas, capazes de não apenas fazer concessões aos sujeitos subalternizados (como acontece sistematicamente na história brasileira), mas de incluí-los, visibilizá-los e das quais participem ativamente na construção. Acreditamos que, dessa maneira, a leitura literária possa ir além das limitações do sistema educativo, do ensino e da transmissão de saber. Defendemos que ela seja formada por práticas e processos sóciopolíticos transformadores, como propõe Walsh (2009), estabelecidos com base nas realidades, subjetividades, histórias e lutas das pessoas que foram sistematicamente oprimidas pela lógica colonial. Essa abordagem vai ao encontro dos ideais educativos propostos por Paulo Freire no decurso de toda a sua obra, e que ainda hoje não alcançaram condições reais para sua materialização plena, precisando ainda ser reafirmados.

Por fim, entendemos a perspectiva da decolonialidade enquanto um projeto de intervenção na realidade que, por esse motivo, possibilita o pensamento crítico sobre a construção histórica de práticas e políticas educacionais que se escamoteiam de inclusivas, mas acabam por reforçar as desigualdades entre grupos sociais distintos. A partir de uma postura decolonial, é preciso/possível valermo-nos do ensino de literatura para questionarmos a noção de geopolítica e corpo-política do conhecimento. Que possamos escutar, e construir em conjunto com os grupos subalternizados um projeto de educação que questione a supremacia branca, o imperialismo, o sexismo, o racismo e o preconceito em qualquer de suas formas (HOOKS, 2013). Como dissemos anteriormente, essa conduta deve estar alinhada a práticas de reexistência que já existem em vários aspectos - acadêmicos e nãoacadêmicos -, por iniciativa de vários grupos sociais de nosso país, buscando cada vez mais dar visibilidades a essas práticas bem como propor outras.

\section{Contribuição dos autores}

Os autores trabalham de maneira conjunta para pensar os ensinos de literaturas/educação literária. Fundaram conjuntamente o grupo de pesquisa "ELINT: Ensino de literaturas: diversidades, mercados e políticas públicas" e desenvolvem trabalhos em parceria, como o presente artigo. Este trabalho nasceu a partir de trocas, questionamentos e incômodos compartilhados. A partir do momento que essa partilha foi crescendo, a decisão foi transformála em um artigo com intuito de que as reflexões elaboradas em texto possam chegar a muitos outros docentes e pesquisadores. 


\section{Referências}

BALLESTRIN, Luciana. América Latina e o giro decolonial. Revista Brasileira de Ciências Políticas, Brasília, n. 11, p. 89-117, maio-ago., 2013. DOI: https://doi. org/10.1590/S0103-33522013000200004

BERNARDINO-COSTA, Joaze et al. Introdução. In: BERNARDINO-COSTA, Joaze; MALDONADO-TORRES, Nelson; GROSFOGUEL, Ramon (org.). Decolonialidade e pensamento afrodiaspórico. Belo Horizonte: Autêntica Editora, 2019. p. 9-26.

BRASIL. Resolução CNE/CEB n. 5, de 22 de junho de 2012. Define Diretrizes Curriculares Nacionais para a Educação Escolar Indígena na Educação Básica. Brasília: Ministério de Educação e Cultura, 2012.

BRASIL. Lei 11.645, de 10 de março de 2008. Altera a Lei n. 9.394, de 20 de dezembro de 1996, modificada pela Lei n. 10.639, de 9 de janeiro de 2003, que estabelece as diretrizes e bases da educação nacional, para incluir no currículo oficial da rede de ensino a obrigatoriedade da temática "História e Cultura Afro-Brasileira e Indígena". Brasília: Ministério de Educação e Cultura; Congresso Nacional, 2008.

BRASIL. Lei 10.639, de 9 de janeiro de 2003. Altera a Lei n. 9.394, de 20 de dezembro de 1996, que estabelece as diretrizes e bases da educação nacional, para incluir no currículo oficial da Rede de Ensino a obrigatoriedade da temática "História e Cultura Afro-Brasileira", e dá outras providências. Brasília: Ministério de Educação e Cultura; Congresso Nacional, 2003.

BRASIL. Lei 9.394, de 20 de dezembro de 1996. Lei das Diretrizes e Bases da Educação Nacional. Estabelece as diretrizes e bases da educação nacional. Brasilia: Ministério de Educação e Cultura; Congresso Nacional, 1996.

BRASIL. Constituição (1988). Constituição da República Federativa do Brasil. Brasília, DF: Senado Federal; Centro Gráfico, 1988.

CANDAU, Vera Maria. Multiculturalismo e educação: desafios para a prática pedagógica. In: MOREIRA, Antonio Flávio; CANDAU, Vera Maria. Multiculturalismo: diferenças culturais e práticas pedagógicas. 10. ed. Petrópolis, RJ: Vozes, 2013. p. 13-37.

GONZALES, Lélia. Por um feminismo afro-latino-americano. In: HOLLANDA, Heloisa Buarque (org.). Pensamento feminista hoje: perspectivais decoloniais. Rio de Janeiro: Bazar do Tempo, 2020. p. 38-51.

HOOKS, Bell. Ensinando a transgredir. a educação como prática de liberdade. Trad. Marcelo Brandão Cipolla. São Paulo: Editora WMF Martins Fontes, 2013. 
LORDE, Audre. Irmã outsider: ensaios e conferências. Trad. Stephanie Borges. Belo Horizonte: Autêntica Editora, 2019.

LUGONES, Maria. Colonialidade e gênero. In: HOLLANDA, Heloisa Buarque (org.). Pensamento feminista hoje: perspectivas decoloniais. Rio de Janeiro: Bazar do Tempo, 2020. p. 52-83.

MALDONADO-TORRES, Nelson. Sobre la colonialidad del ser: contribuciones al desarrollo de un concepto. In: CASTRO-GOMÉZ, Santiago; GROSFOGUEL, Ramon (org.). El giro decolonial: reflexiones para una diversidad epistémica más allá del capitalismo global. Bogotá: Siglo del Hombre Editores; Universidad Central, Instituto de Estudios Sociales Contemporáneos y Pontificia Universidad Javeriana. Instituto Pensar, 2007. p. 127-159.

MATA, Inocência. Estudos pós-coloniais: desconstruindo genealogias eurocêntricas. Revista Civitas, Porto Alegre, v 14, n. 1, Dossiê: Diálogos do Sul, p. 27-42, jan./abr. 2014. DOI: https://doi.org/10.15448/1984-7289.2014.1.16185

MIGNOLO, Walter. El piensamiento decolonial: desprendimiento e apertura. Un manifesto. In: CASTRO-GÓMEZ, Santiago; GROSFOGUEL, Ramón. (org.). El giro decolonial: reflexiones para una diversidade epistémica más allá del capitalismo global. Bogotá: Siglo del Hombre Editores; Universidad Central, Instituto de Estudios Sociales Contemporáneos y Pontificia Universidad Javeriana; Instituto Pensar, 2007. p. 25-46.

PORTO-GONÇALVES, Carlos Walter. Apresentação da edição em português. In: LANDER, Edgardo (org.). A colonialidade do saber: eurocentrismo e ciências sociais. Perspectivas latinoamericanas. Ciudad Autónoma de Buenos Aires: Colección Sur Sur, CLACSO, 2005. p. 3-5.

QUIJANO, Aníbal. Colonialidade do poder, eurocentrismo e América Latina. In: LANDER, Edgardo (org.). A colonialidade do saber: eurocentrismo e ciências sociais. Perspectivas latinoamericanas. Ciudad Autónoma de Buenos Aires: Colección Sur Sur, CLACSO, 2005. p. 107-130.

QUIJANO, Aníbal. Colonialidad del poder y classificacíon social. In: CASTROGÓMEZ, Santiago; GROSFOGUEL, Ramón. (org.). El giro decolonial: reflexiones para una diversidade epistémica más allá del capitalismo global. Bogotá: Siglo del Hombre Editores; Universidad Central, Instituto de Estudios Sociales Contemporáneos y Pontificia Universidad Javeriana, Instituto Pensar, 2007. p. 93-126

SOARES, Magda. Leitura e democracia cultural. In: PAIVA, Aparecida; MARTINS, Aracy; PAULINO, Graça; VERSINANI, Zélia (org.). Democratizando a leitura: pesquisas e práticas. Belo Horizonte: Autêntica: Ceale, 2008. p. 17-32. 
WALSH, Catherine. Interculturalidad crítica y pedagogia de-colonial: apuestas (des) de el in-surgir, re-existir e re-vivir. Revista (entre palabras), Quito, v. 3, p. 1-29, 2009. ZILBERMAN, Regina. A teoria da literatura e a leitura na escola. In: . $A$ literatura e o ensino da literatura. Curitiba: InterSaberes, 2012. p. 236-248. 